\title{
Treatment of Severe Metastatic Calcification and Calciphylaxis in Dialysis Patients
}

\author{
Saurabh K. Goel, ${ }^{1}$ Keith Bellovich, ${ }^{1}$ and Peter A. McCullough ${ }^{2}$ \\ ${ }^{1}$ Division of Nephrology, St. John Providence Health System, St. John Hospital and Medical Center, \\ 22201 Moross Road, Suite 150, Detroit, MI 48236, USA \\ ${ }^{2}$ St. John Providence Health System, Providence Park Heart Institute, Novi, MI 48374, USA
}

Correspondence should be addressed to Saurabh K. Goel, drsaurabh2004@yahoo.com

Received 26 October 2010; Accepted 20 December 2010

Academic Editor: Biagio Raffaele Di Iorio

Copyright (C) 2011 Saurabh K. Goel et al. This is an open access article distributed under the Creative Commons Attribution License, which permits unrestricted use, distribution, and reproduction in any medium, provided the original work is properly cited.

Metastatic calcification is a frequent complication encountered in patients undergoing maintenance dialysis and has a complex pathogenesis. It is often difficult to treat and is associated with high morbidity and mortality. Early recognition and prompt initiation of treatment is vital. Local wound care and aggressive metabolic control remain the cornerstones of the therapy. Various novel treatment strategies including sodium thiosulfate and hyperbaric oxygen therapy have been utilized and reviewed in this paper. The response rate to treatment is poor and prevention is the best approach.

\section{Introduction}

Extraskeletal metastatic calcifications are seen frequently in patients undergoing maintenance dialysis, and the incidence increases with dialysis vintage [1]. Calciphylaxis is a rare but life-threatening form, characterized by systemic medial calcification of the arterioles leading to ischemia and subcutaneous necrosis. It is reported to occur from as little as 1 month to as long as 12 years after the onset of end-stage renal disease (ESRD), with a median time of 2 years and 9 months [2]. The term "calciphylaxis" was coined in 1962 by Hans Selye, who used it to describe a systemic anaphylactic reaction leading to soft-tissue and vascular calcification in animal models [3]. It continues to be used widely to describe the phenomenon in humans, despite the introduction of "calcific uremic arteriolopathy" (CUA) as a more descriptive term. The incidence of this condition appears to be increasing, due in part to the use of calcium-based phosphate binders and vitamin D analogs for the treatment of severe hyperparathyroidism [4]. Another contributing factor is a greater awareness and recognition of clinical signs and risk factors associated with calciphylaxis. It is estimated to have an incidence of $1 \%$ per year [5] and a prevalence of $4.1 \%$ in dialysis patients [1], with preponderance among obese, Caucasian females $[2,5,6]$ and diabetic patients [7]. Reports to the Australian and New Zealand Dialysis and Transplant Registry (ANZDATA) identified calciphylaxis as a cause of death in 64 patients (from 1985 until March 2004) and listed it as a comorbid condition in 86 cases [8].

Slowly progressive metastatic calcifications are much more common than calciphylaxis in patients with end-stage renal disease. Common sites of involvement are the blood vessels, periarticular regions, heart, lungs, kidneys, gastric mucosa, central nervous system, breasts, and eyes. The liver, spleen, skeletal muscle, small and large bowel, peritoneal cavity, tongue, and larynx are less commonly affected [9].

\section{Pathogenesis}

The pathogenesis of calciphylaxis is complex and poorly understood. Intimal fibrosis, mural calcifications of the dermohypodermic arterioles, and vascular thrombus formation all reduce arteriolar blood flow leading to microvascular ischemia [10]. This results in areas of painful ischemic necrosis in the dermis and subcutaneous fat, mainly involving the abdomen, buttocks, and medial aspects of the 


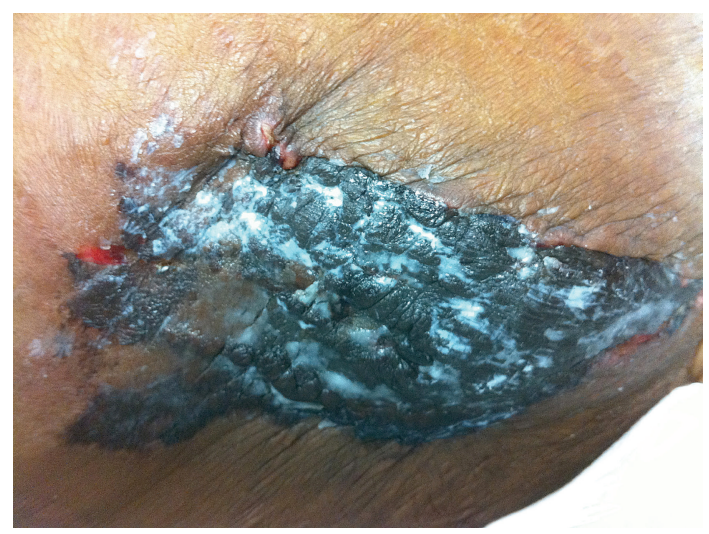

Figure 1: A large, necrotic, nonhealing ulceration on the abdomen of a patient with end stage renal disease, typical of a calciphylactic lesion.

thighs. It manifests as livedo reticularis and/or violaceous, painful, plaque-like subcutaneous nodules, which progress to ischemic/necrotic ulcers with eschars that often become superinfected (Figure 1). Less commonly involved organs and muscle groups include kidneys, heart, skeletal muscle, lungs, and gastrointestinal tract [11]. Abnormalities in mineral metabolism including hyperphosphatemia [6], hyperparathyroidism [12], an elevated plasma calcium and phosphate product [13] and active vitamin D supplementation [14] and deficiency of inhibitors of vascular calcifications, such as fetuin-A $[15,16]$ and matrix Gla protein [17], have all been implicated in this process. High level of 1,25-dihydroxy vitamin $\mathrm{D}_{3}$ has been associated with deleterious effect on the vascular smooth muscle cell (SMC) phenotype causing medial wall calcification, suppression of endogenous inhibitors of SMC calcification, stimulation of SMC expression of alkaline phosphatase, and low bone turnover leading to hyperphosphatemia and hypercalcemia [14]. In the only prospective trial of CUA, the declining use of calcium salts was associated with a decline in incidence [18]. Chronic inflammatory states including autoimmune disorders [19] and hypercoagulable states such as protein C and protein $S$ deficiency $[20,21]$ have also been identified as potential contributors. Administration of certain medications including warfarin [22], systemic corticosteroids [23], iron-dextran [24], erythropoietin [6], and albumin [25] has been reported to be associated with calciphylaxis.

\section{Diagnosis}

Early recognition is the key to better treatment outcomes. In lieu of any specific laboratory tests, the diagnosis is most often clinical, made apparent by the presence of proximal ulcers, intact peripheral pulses and the absence of neuropathy in a patient with the above-mentioned risk factors. The noninvasive tests including plain radiographs, high-resolution computed tomography, bone scans, and Xray mammography are nonspecific for this condition. In the absence of contraindications, the diagnosis may be confirmed by skin biopsy, which reveals calcifying septal panniculitis and arterial occlusion and calcification in the absence of vasculitic changes [26]. Skin biopsy may invite further infection in the presence of an active infection, can initiate ulcer formation and propagation, and is subject to sampling error. Thus, it should be performed only after considering and discussing the risks and benefits of the procedure with the patient.

\section{Prognosis}

Calciphylaxis continues to be a lethal complication with an estimated one-year survival rate of 45.8 percent [23]. The presence of advanced disease at the time of therapy and proximal ischemic lesions are poor prognostic features. Ulceration carries a mortality of greater than 80 percent as a result of local and systemic infections and sepsis [7].

\section{Treatment Approach}

The optimal therapy of calciphylaxis is to prevent its development by rigorous control of phosphate and calcium balance while avoiding or modifying the other risk factors. Unfortunately, no randomized controlled trials are available to guide management of affected patients. A multidisciplinary therapeutic approach is recommended in those with established disease, focusing on local wound care and metabolic control.

An aggressive local wound care program should be initiated to prevent local and systemic infections [11]. This typically involves the use of enzymatic debriding agents, wetto-dry dressings, hydrocolloid or hydrogel dressings, and systemic antibiotics as needed for infections and avoidance of local tissue trauma, including subcutaneous injections.

The role of surgical debridement for ulcerations in this condition remains controversial [23]. Improved survival rates have been documented; however, it predisposes the patient to increased risk of sepsis and worsening pain. A pain management specialist should be consulted to provide adequate pain control anticipating a prolonged duration of persistent discomfort. Emotional support should be provided to the patient and family, as calciphylaxis is very painful and debilitating disease. Nutritional status of the patient should be well addressed. An increase in dietary protein has been shown to promote wound healing in patients with low serum protein [11].

Every effort should be made to correct the underlying abnormalities in plasma calcium and phosphorus concentrations aiming for a target calcium and phosphorus product below 55 and serum levels of phosphate between 2.7 and $4.6 \mathrm{mg} / \mathrm{dL}$ [27]. A diet low in calcium and phosphate should be strictly followed. Noncalcium-containing phosphate binders, such as sevelamer carbonate or lanthanum carbonate, rather than calcium-based phosphate binders should be administered as the latter increase the rate of hypercalcemia [28]. Though no study has demonstrated that the use of more frequent dialysis sessions or high-flux hemodialysis membranes alter the long-term outcome, the dialysis dose should be increased in patients with inadequate 
clearance [28]. A low-calcium-containing dialysis solution (for both hemodialysis and peritoneal dialysis) may be used to lower serum calcium levels [29], but their success alone in healing the lesions remains unproven. Since the activity of matrix Gla protein is dependent on vitamin $\mathrm{K}$ carboxylation, discontinuation of warfarin therapy should be strongly considered.

Normalization of serum parathyroid hormone (PTH) levels should be attempted using cinacalcet rather than vitamin D analogues, as the latter tends to raise the calcium and phosphate product. Cinacalcet may serve as an alternative to parathyroidectomy for the correction of secondary hyperparathyroidism [30]. However, parathyroidectomy should still be considered for patients with refractory hyperparathyroidism. Parathyroidectomy has been shown to provide pain relief and improve wound healing and short-term mortality, yet the long-term benefits are still unknown $[5,12,31]$.

\section{Novel Therapies}

Sodium Thiosulfate. Sodium thiosulfate has been used therapeutically for more than one hundred years for a variety of conditions including acute cyanide poisoning, recurrent calcium urolithiasis, nephrocalcinosis, and tumoral calcinosis. Intravenous sodium thiosulfate has been increasingly used as an adjunctive treatment in patients with debilitating calciphylactic necrotic lesions [32, 33]. Marked improvements with reduction of pain and inflammation and improved healing of ulcerative lesions have been demonstrated within a few days to six months of use. The proposed mechanism of action is that it dissolves insoluble calcium salts embedded in tissue into soluble calcium thiosulfate. Other proposed mechanisms include reversal of endothelial dysfunction and increased vasodilatation through its antioxidant properties. It is generally considered to be a safe and nontoxic drug. Sulfate retention causing increased anion gap metabolic acidosis has been occasionally reported with no documented morbidity or mortality in humans at the doses used clinically. The reported doses vary from 5 to 25 grams intravenously, three to four times per week for a period of 6 to 24 months. However, the optimum dosage schedule and duration of treatment remains to be determined.

Bisphosphonates. Bisphosphonates have a powerful inhibitory effect on osteoclast activity and bone resorption and are largely used in treatment of osteoporosis, tumoral hypercalcemia, and Paget's disease. They have also been shown to exert an inhibitory effect on macrophage activity and local proinflammatory cytokine production. Animal models and few case reports have shown improvement of calciphylaxis lesions associated with systemic inflammatory response, when treated with intravenous pamidronate and oral etidronate $[34,35]$. This benefit has been ascribed more to their anti-inflammatory effect than to their effects on calcium metabolism.

Hyperbaric Oxygen Therapy (HBO). HBO consists of breathing $100 \%$ oxygen at a pressure higher than ambient atmospheric pressure (1 atmosphere absolute) while the patient is situated inside a sealed treatment chamber. Healing is impaired when tissue oxygen tension falls below $20 \mathrm{mmHg}$. Hypoxia also hinders with the oxygen-dependent polymorphonuclear leukocyte-mediated bacterial killing in the wound infections. HBO therapy increases the amount of oxygen in diseased tissue thereby promoting wound healing. $\mathrm{HBO}$ at 2.5 atmospheres absolute has been used for 90 minutes, 5 days per week for 5 to 7 consecutive weeks in reported cases. The therapy has been shown to be beneficial in healing cutaneous ulcers of calciphylaxis in some patients; however, the treatments are costly and not readily available. It may also increase the pain in some patients and remains ineffective with organ involvement [36].

Steroids. The use of corticosteroids in the treatment of calciphylaxis remains controversial. In a single case report, the use of prednisone resulted in stabilization or improvement in nonulcerating lesions [7]; however, it may predispose the patient to systemic infection [11]. Moreover, systemic corticosteroids have even been reported to be a risk factor for calciphylaxis in non-ESRD patients with an autoimmune disorder [23].

Sterile Maggot Therapy. Larvae of the species Lucilia sericata have been used to debride and disinfect skin lesions of calciphylaxis. The maggots have enzymes that liquefy necrotic tissue and secrete phenylacetic acid and phenylacetyl aldehyde, which have antibacterial activity that helps to prevent infection [37]. This treatment is almost painless, and results have been promising. The risks and long-term outcomes still need to be assessed.

Anticoagulation Therapy. There have been case reports of use of low-dose tissue plasminogen activator [38] and substitution of warfarin with low molecular weight heparin [22] with proven benefit in calciphylaxis.

Limb Revascularization. Limb revascularization has been attempted to treat distal wound involvement, but gangrene and lower-extremity ischemia continues to progress in many patients, and the outcomes have been poor [39]. It is debatable whether primary amputation should be the treatment of lower-extremity calciphylaxis when ischemia is also present.

Response to any therapy is assessed principally by physical examination. The disease continues to have high morbidity and mortality with poor response to any therapeutic regimen. Thus, early recognition and prompt initiation of multidisciplinary treatment measures is vital.

\section{Conclusions}

Calciphylaxis is a severe form of metastatic calcification seen in ESRD patients undergoing maintenance hemodialysis. It often presents as ischemic skin ulceration and is associated with high morbidity and mortality. Abnormal mineral and bone metabolism is the strongest risk factor, and its correction along with local wound care is the cornerstone 
of the therapy. However, prevention is the best approach as the outcomes remain poor despite many novel treatment modalities.

\section{Abbreviations}

ESRD: End stage renal disease

CUA: Calcific uremic arteriolopathy

SMC: Vascular smooth muscle cell

HBO: Hyperbaric oxygen therapy

PTH: Parathyroid hormone.

\section{References}

[1] M. Angelis, L. L. Wong, S. A. Myers, and L. M. Wong, "Calciphylaxis in patients on hemodialysis: a prevalence study," Surgery, vol. 122, no. 6, pp. 1083-1090, 1997.

[2] M. N. Budisavljevic, D. Cheek, and D. W. Ploth, "Calciphylaxis in chronic renal failure," Journal of the American Society of Nephrology, vol. 7, no. 7, pp. 978-982, 1996.

[3] H. Selye, Calciphylaxis, University of Chicago Press, Chicago, Ill, USA, 1962.

[4] J. M. Zacharias, B. Fontaine, and A. Fine, "Calcium use increases risk of calciphylaxis: a case-control study," Peritoneal Dialysis International, vol. 19, no. 3, pp. 248-252, 1999.

[5] J. Hafner, G. Keusch, C. Wahl, and G. Burg, "Calciphylaxis: a syndrome of skin necrosis and acral gangrene in chronic renal failure," Vasa, vol. 27, no. 3, pp. 137-143, 1998.

[6] A. R. Mazhar, R. J. Johnson, D. Gillen et al., "Risk factors and mortality associated with calciphylaxis in end-stage renal disease," Kidney International, vol. 60, no. 1, pp. 324-332, 2001.

[7] A. Fine and J. Zacharias, "Calciphylaxis is usually nonulcerating: risk factors, outcome and therapy," Kidney International, vol. 61, no. 6, pp. 2210-2217, 2002.

[8] S. P. McDonald and L. Excell, "ANZDATA Registry Report," Adelaide, Australia, 2005.

[9] D. N. S. Kerr, "Hypercalcemia and metastatic calcification," Cardiovascular Research, vol. 36, no. 3, pp. 293-297, 1997.

[10] R. H. Weenig, "Pathogenesis of calciphylaxis: Hans Selye to nuclear factor $\kappa$-B," Journal of the American Academy of Dermatology, vol. 58, no. 3, pp. 458-471, 2008.

[11] B. Hahler, "Calciphylaxis in the patient with chronic renal failure," Dermatology Nursing, vol. 13, no. 6, pp. 435-449, 2001.

[12] R. M. Gipstein, J. W. Coburn, and D. A. Adams, "Calciphylaxis in man. A syndrome of tissue necrosis and vascular calcification in 11 patients with chronic renal failure," Archives of Internal Medicine, vol. 136, no. 11, pp. 1273-1280, 1976.

[13] Block, "Hyperphosphatemia has been regarded as a risk factor for calciphylaxis," Clinical Nephrology, vol. 54, pp. 318-324, 2000.

[14] W. A. Wilmer and C. M. Magro, "Calciphylaxis: emerging concepts in prevention, diagnosis, and treatment," Seminars in Dialysis, vol. 15, no. 3, pp. 172-186, 2002.

[15] P. A. Price, M. K. Williamson, T. M. T. Nguyen, and T. N. Than, "Serum levels of the fetuin-mineral complex correlate with artery calcification in the rat," Journal of Biological Chemistry, vol. 279, no. 3, pp. 1594-1600, 2004.

[16] M. Ketteler, P. Bongartz, R. Westenfeld et al., "Association of low fetuin-A (AHSG) concentrations in serum with cardiovascular mortality in patients on dialysis: a cross-sectional study," The Lancet, vol. 361, no. 9360, pp. 827-833, 2003.
[17] G. Luo, P. Ducy, M. D. McKee et al., "Spontaneous calcification of arteries and cartilage in mice lacking matrix GLA protien," Nature, vol. 386, no. 6620, pp. 78-81, 1997.

[18] A. Fine and B. Fontaine, "Calciphylaxis: the beginning of the end?" Peritoneal Dialysis International, vol. 28, no. 3, pp. 268270, 2008.

[19] S. Slough, K. S. Servilla, A. M. Harford, K. N. Konstantinov, A. Harris, and A. H. Tzamaloukas, "Association between calciphylaxis and inflammation in two patients on chronic dialysis," Advances in Peritoneal Dialysis, vol. 22, pp. 171-174, 2006.

[20] R. L. Mehta, G. Scott, J. A. Sloand, and C. W. Francis, "Skin necrosis associated with acquired protein $\mathrm{C}$ deficiency in patients with renal failure and calciphylaxis," American Journal of Medicine, vol. 88, no. 3, pp. 252-257, 1990.

[21] L. Rostaing, S. El Feki, M. B. Delisle et al., "Calciphylaxis in a chronic hemodialysis patient with protein $S$ deficiency," American Journal of Nephrology, vol. 15, no. 6, pp. 524-527, 1995.

[22] T. Coates, G. S. Kirkland, R. B. Dymock et al., "Cutaneous necrosis from calcific uremic arteriolopathy," American Journal of Kidney Diseases, vol. 32, no. 3, pp. 384-391, 1998.

[23] R. H. Weenig, L. D. Sewell, M. D. P. Davis, J. T. McCarthy, and M. R. Pittelkow, "Calciphylaxis: natural history, risk factor analysis, and outcome," Journal of the American Academy of Dermatology, vol. 56, no. 4, pp. 569-579, 2007.

[24] D. Rubinger, M. M. Friedlaender, and J. Silver, "Progressive vascular calcification with necrosis of extremities in hemodialysis patients: a possible role of iron overload," American Journal of Kidney Diseases, vol. 7, no. 2, pp. 125-129, 1986.

[25] R. D. Solomon, B. B. Nadkarni, and L. Richardson, "Local calciphylaxis in dihydrotachysterol-sensitized rats. The role of alkaline phosphatase," Archives of Pathology, vol. 82, no. 1, pp. 60-64, 1966.

[26] L. R. Essary and M. R. Wick, "Cutaneous calciphylaxis: an underrecognized clinicopathologic entity," American Journal of Clinical Pathology, vol. 113, no. 2, pp. 280-287, 2000.

[27] "KDIGO clinical practice guidelines for the diagnosis, evaluation, prevention, and treatment of chronic kidney diseasemineral and bone disorder," Kidney International, vol. 72, no. S113, pp. S1-S130, 2009.

[28] R. Russell, M. A. Brookshire, M. Zekonis, and S. M. Moe, "Distal calcific uremic arteriolopathy in a hemodialysis patient responds to lowering of $\mathrm{Ca} \times \mathrm{P}$ product and aggressive wound care," Clinical Nephrology, vol. 58, no. 3, pp. 238-243, 2002.

[29] D. Lipsker, O. Chosidow, F. Martinez, E. Challier, and C. Frances, "Low-calcium dialysis in calciphylaxis," Archives of Dermatology, vol. 133, no. 6, pp. 798-796, 1997.

[30] N. Velasco, M. S. MacGregor, A. Innes, and I. G. MacKay, "Successful treatment of calciphylaxis with cinacalcet-an alternative to parathyroidectomy?" Nephrology Dialysis Transplantation, vol. 21, no. 7, pp. 1999-2004, 2006.

[31] A. S. Kang, J. T. McCarthy, C. Rowland et al., "Is calciphylaxis best treated surgically or medically?" Surgery, vol. 128, no. 6, pp. 967-972, 2000.

[32] J. S. Cicone, J. B. Petronis, C. D. Embert, and D. A. Spector, "Successful treatment of calciphylaxis with intravenous sodium thiosulfate," American Journal of Kidney Diseases, vol. 43, no. 6, pp. 1104-1108, 2004.

[33] M. R. Hayden and D. J.A. Goldsmith, "Sodium thiosulfate: new hope for the treatment of calciphylaxis," Seminars in Dialysis, vol. 23, no. 3, pp. 258-262, 2010.

[34] P. Monney, Q. V. Nguyen, H. Perroud, and E. Descombes, "Rapid improvement of calciphylaxis after intravenous 
pamidronate therapy in a patient with chronic renal failure," Nephrology Dialysis Transplantation, vol. 19, no. 8, pp. 21302132, 2004.

[35] N. Shiraishi, K. Kitamura, T. Miyoshi et al., "Successful treatment of a patient with severe calcific uremic arteriolopathy (calciphylaxis) by etidronate disodium," American Journal of Kidney Diseases, vol. 48, no. 1, pp. 151-154, 2006.

[36] C. Basile, A. Montanaro, M. Masi, G. Pati, P. De Maio, and A. Gismondi, "Hyperbaric oxygen therapy for calcific uremic arteriolopathy: a case series," Journal of Nephrology, vol. 15, no. 6, pp. 676-680, 2002.

[37] J. Tittelbach, T. Graefe, and U. Wollina, "Painful ulcers in calciphylaxis - combined treatment with maggot therapy and oral pentoxyfillin," Journal of Dermatological Treatment, vol. 12, no. 4, pp. 211-214, 2001.

[38] L. D. Sewell, R. H. Weenig, M. D. P. Davis, M. T. McEvoy, and M. R. Pittelkow, "Low-dose tissue plasminogen activator for calciphylaxis," Archives of Dermatology, vol. 140, no. 9, pp. 1045-1048, 2004.

[39] S. G. Friedman, "Leg revascularization in patients with calciphylaxis," American Surgeon, vol. 68, no. 7, pp. 591-592, 2002. 


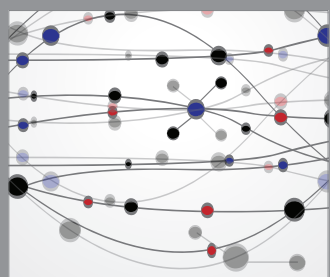

The Scientific World Journal
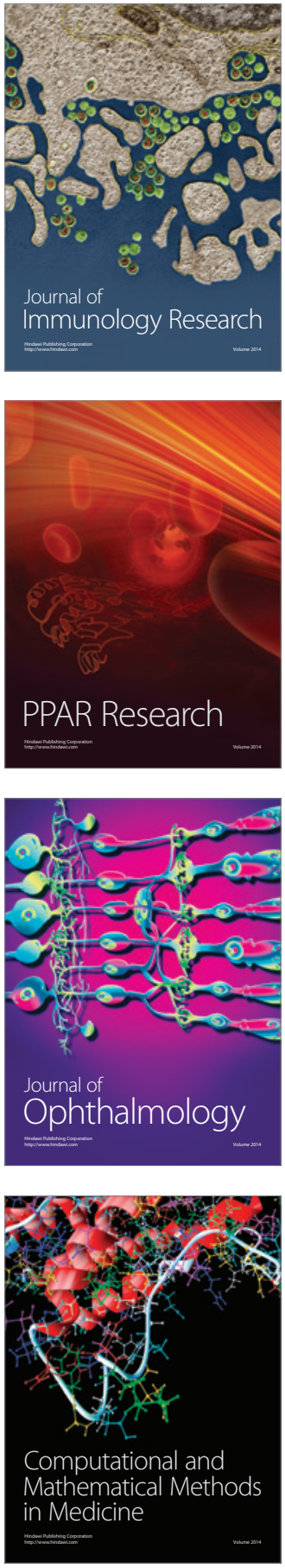

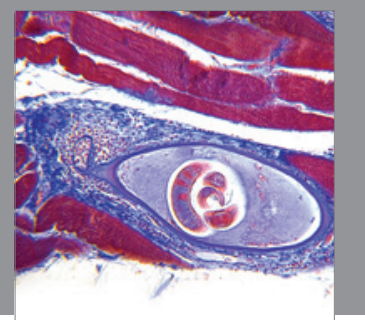

Gastroenterology

Research and Practice
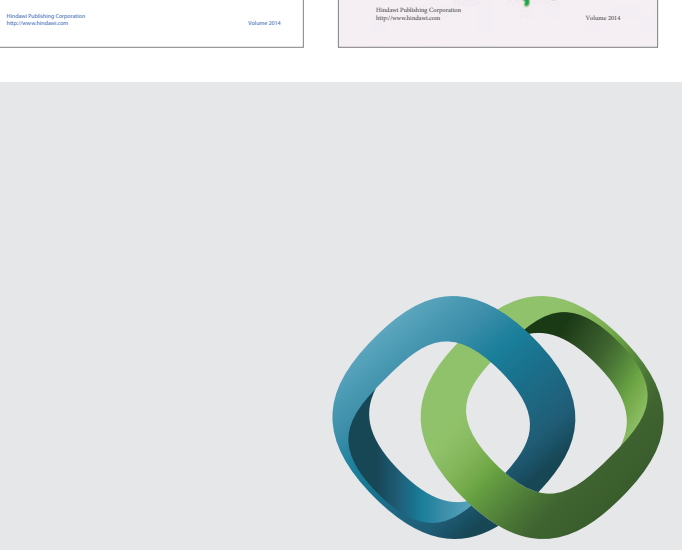

\section{Hindawi}

Submit your manuscripts at

http://www.hindawi.com
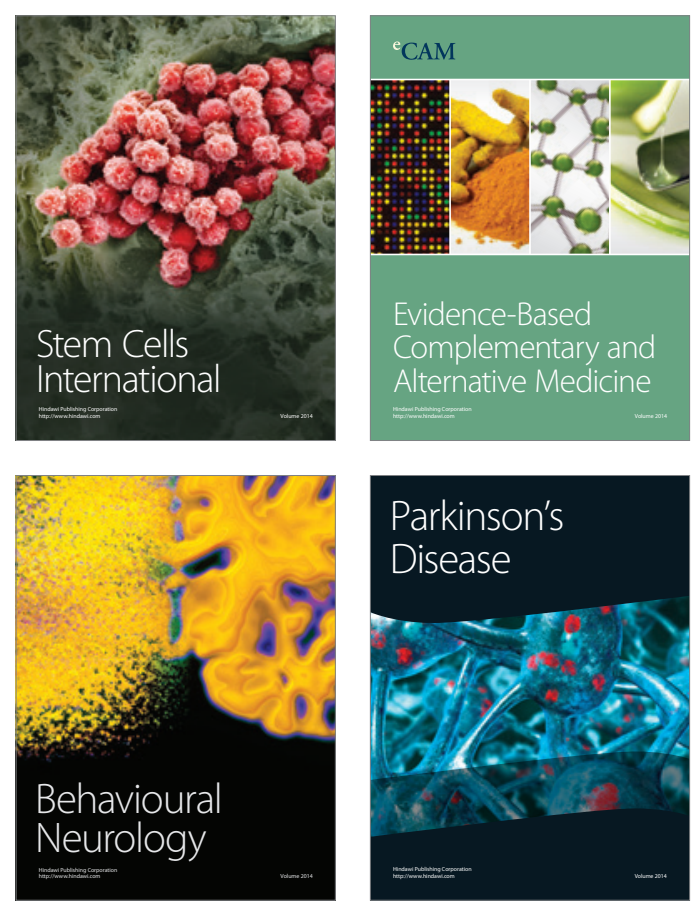

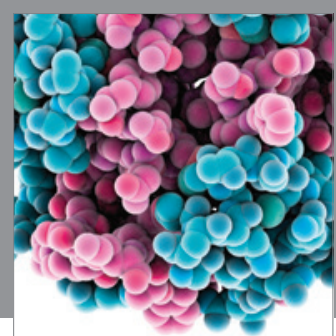

Journal of
Diabetes Research

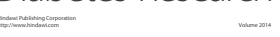

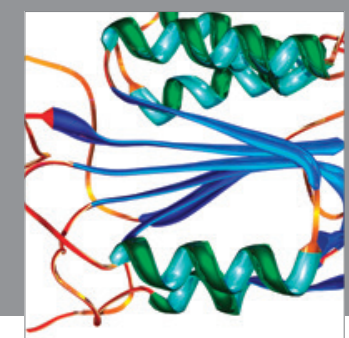

Disease Markers
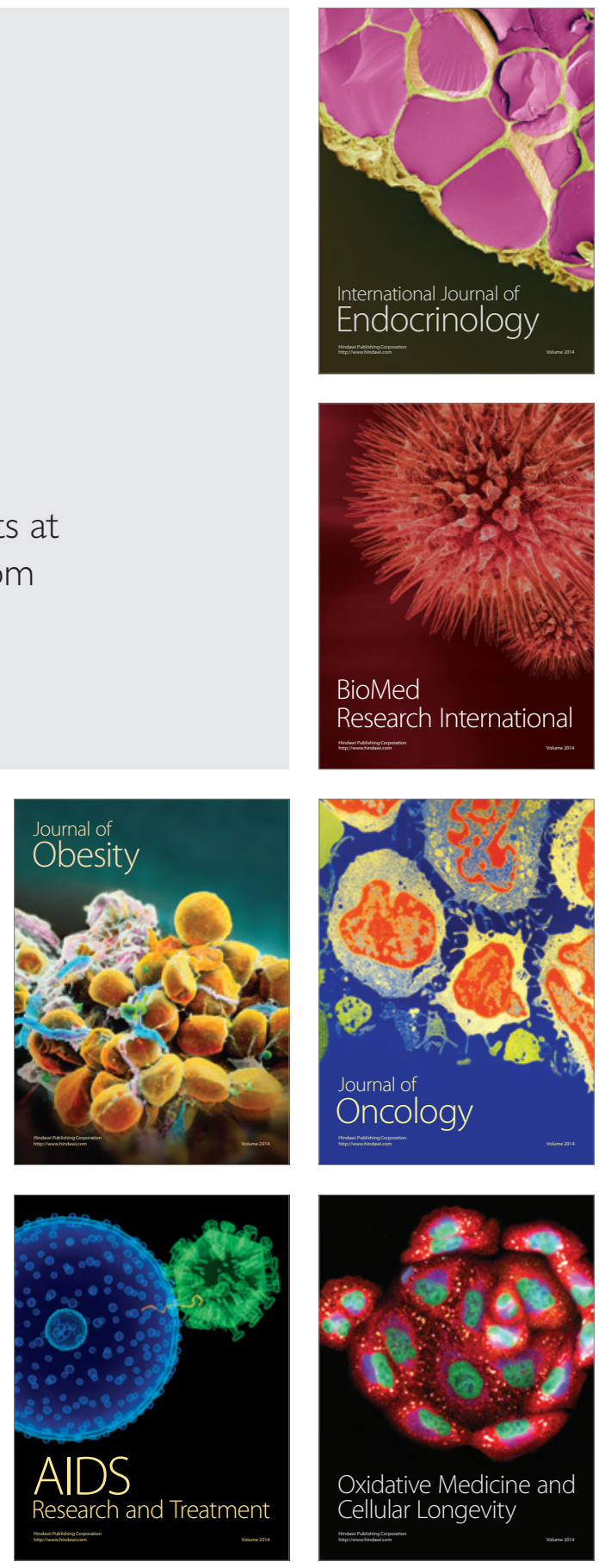